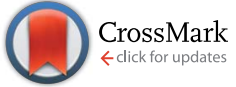

Cite this: RSC Adv., 2015, 5, 78142

Received 26th June 2015

Accepted 4th September 2015

DOI: $10.1039 / c 5 r a 12388 g$

www.rsc.org/advances

\section{Aggregate-based sub-CMC solubilization of hexadecane by surfactants $\uparrow$}

\author{
Hua Zhong, ${ }^{\text {*abc }}$ Lei Yang, ${ }^{\text {ab }}$ Guangming Zeng, ${ }^{\text {ab }}$ Mark L. Brusseau, ${ }^{c}$ Yake Wang, ${ }^{c}$ \\ Yang Li, ${ }^{d}$ Zhifeng Liu, ${ }^{\text {ab }}$ Xingzhong Yuan ${ }^{\text {ab }}$ and Fei Tan ${ }^{\text {ab }}$
}

Solubilizaiton of hexadecane by two surfactants, SDBS and Triton X-100, at concentrations near the critical micelle concentration (CMC) and the related aggregation behavior was investigated in this study. Solubilization was observed at surfactant concentrations lower than CMC, and the apparent solubility of hexadecane increased linearly with surfactant concentration for both surfactants. The capacity of SDBS to solubilize hexadecane is stronger at concentrations below CMC than above CMC. In contrast, Triton $\mathrm{X}-100$ shows no difference. The results of dynamic light scattering (DLS) and cryogenic TEM analysis show aggregate formation at surfactant concentrations lower than CMC. DLS-based size of the aggregates $(d)$ decreases with increasing surfactant concentration. The zeta potential of the SDBS aggregates decreases with increasing SDBS concentration, whereas it increases for Triton X-100. The surface excess $(T)$ of SDBS calculated based on hexadecane solubility and aggregate size data increases rapidly with increasing bulk concentration, and then asymptotically approaches the maximum surface excess $\left(\Gamma_{\text {max }}\right)$. Conversely, there is only a minor increase in $I$ for Triton X-100. Comparison of $I$ and $d$ indicates that an excess of surfactant molecules at the aggregate surface has a great impact on surface curvature. The results of this study demonstrate the formation of aggregates at surfactant concentrations below CMC for hexadecane solubilization, and indicate the potential of employing a low-concentration strategy for surfactant applications such as remediation of HOC contaminated sites.

\section{Introduction}

Surfactants are used for a myriad of industrial and household applications. One well-known function of surfactants is to solubilize hydrophobic organic compounds (HOCs). This function has been employed for many purposes, ranging from oily dirt removal from textiles to enhanced remediation of soil or groundwater contaminated by HOCs. ${ }^{1-3}$ Solubilization enhancement of HOCs by surfactants has been the subject of many experimental and theoretical studies, especially at concentrations above CMCs. ${ }^{4-10}$ The critical micelle concentration (CMC) is generally considered to be the concentration at which surfactant molecules aggregate to form micelles. Micelles

${ }^{a}$ College of Environmental Science and Engineering, Hunan University, Changsha 410082, China. E-mail: zhonghua@email.arizona.edu; whyanglei@126.com; zgming@hnu.edu.cn; lzf18182002@163.com; yxz@hnu.edu.cn; tanfei_2013@163. com

${ }^{b}$ Key Laboratory of Environmental Biology and Pollution Control (Hunan University), Ministry of Education, Changsha, 410082, China

'Department of Soil, Water and Environmental Science, University of Arizona, Tucson, Arizona 85721, USA.E-mail: brusseau@email.arizona.edu; yakew@email.arizona.edu ${ }^{d}$ Department of Chemistry, University of Science and Technology of China, Hefei, 230026, China. E-mail: ly2013fi@mail.ustc.edu.cn

$\dagger$ Electronic supplementary information (ESI) available. See DOI: $10.1039 / \mathrm{c} 5 \mathrm{ra} 12388 \mathrm{~g}$ are considered to be of spherical shape, and the size, shape, aggregation number, and stability of micelles vary according to temperature, surfactant concentration, and solution chemistry. ${ }^{11}$ It is typically assumed that surfactants solubilize lowsolubility compounds only at concentrations higher than CMC, through partitioning into the hydrophobic core of the micelles. ${ }^{9,12,13}$

The results of some studies have shown, however, that solubilization enhancement may also occur at surfactant concentration below the CMC. Zhang and Miller ${ }^{6}$ investigated solubilization of octadecane by rhamnolipid biosurfactant. Solubilization of octadecane was enhanced by rhamnolipid at concentrations below CMC, and the enhancement was much more significant than above CMC. Similar results were observed for hexadecane solubilization in the presence of a monorhamnolipid in our prior study. ${ }^{14}$ Kile and Chiou investigated solubilization of DDT by surfactants Triton and Brij, and enhancement of apparent DDT solubility was also observed below the nominal CMC. ${ }^{5}$ To our knowledge, the mechanisms for these observations of sub-CMC solubilization, for example the potential for aggregate formation below CMC, have not been systematically investigated in prior studies. Moreover, concern about the ecotoxicology of surfactants, e.g. alkylphenol ethoxylates (APEs), ${ }^{\mathbf{1 5 , 1 6}}$ has caused the implementation of strict emission controls for APEs in various industrial and consumer 
applications. ${ }^{17-20}$ Thus, the ability for surfactants to achieve solubilization enhancement of HOCs at sub-CMC concentrations is of importance for cost and ecotoxicology considerations.

In this study, solubilization of $n$-hexadecane in the presence of SDBS or Triton X-100 surfactant was investigated, with a special focus on such behavior at surfactant concentrations below CMC. SDBS and Triton X-100 were selected to represent anionic and nonionic surfactants, respectively. In addition to hexadecane solubility, characterizations of the potential aggregation of the surfactants, such as aggregate particle size and zeta potential measurements and cryo-TEM-based aggregate observation, were implemented. Finally, based on surfactant interface adsorption theory, spherical aggregate assumption and surfactant mass balance, the aggregation formation and surfactant partitioning mechanism was proposed to interpret the sub-CMC hydrocarbon solubilization.

\section{Theoretical}

At a given temperature, adsorption of surfactant to the hexadecane/aqueous solution interface is related to interfacial tension and surfactant bulk activity as expressed by the Gibbs adsorption equation. ${ }^{21}$ In this study, the adsorption of ionic and nonionic surfactant at the interface in the presence of swamping counterion (electrolyte solution) can be described by eqn (1):

$$
\Gamma=-\frac{a}{R T}\left(\frac{\mathrm{d} \gamma}{\mathrm{d} a}\right) \times 10^{-3}
$$

where $a$ is the surfactant bulk activity $\left(\mathrm{mol} \mathrm{L}^{-1}\right) ; R$ is the universal gas constant $\left(8.314 \mathrm{~J} \mathrm{~mol}^{-1} \mathrm{~K}^{-1}\right), T(\mathrm{~K})$ is the absolute temperature; $\Gamma\left(\mathrm{mol} \mathrm{m}^{-2}\right)$ is the interface excess of the surfactant; $\gamma\left(\mathrm{mN} \mathrm{m}^{-1}\right)$ is the interfacial tension.

Surfactant adsorption at fluid-fluid interfaces is described by the Langmuir equation at concentrations below the critical micelle concentration (CMC): ${ }^{\mathbf{8}, 22}$

$$
\Gamma=\Gamma_{\max } \frac{K a}{1+K a}
$$

where $\left.\Gamma_{\max }(\mathrm{mol} \mathrm{m})^{-2}\right)$ is the maximum interface excess of surfactant and $K\left(\mathrm{~L} \mathrm{~mol}^{-1}\right)$ is the Langmuir constant.

Resolving eqn (1) and combining it with eqn (2) give the Szyszkowski equation, which describes interfacial tension as a function of surfactant bulk activity at concentrations below CMC:

$$
\gamma_{0}-\gamma=R T \Gamma_{\max } \ln (1+K a) \times 10^{3}
$$

where $\gamma_{0}\left(\mathrm{mN} \mathrm{m}^{-1}\right)$ is the interfacial tension of the solution in the absence of surfactant. The relation between $a$ and the freelydissolved surfactant monomer concentration, $C_{\mathrm{w}}\left(\mathrm{mol} \mathrm{L}^{-1}\right)$, is:

$$
a=f C_{\mathrm{w}}
$$

where $f$ is the activity coefficient of surfactant. The concentration of surfactants in bulk solution is relatively low $(<0.01$ mol L ${ }^{-1}$ ) in this study, thus $f$ is very close to 1 and $a \approx C_{\mathrm{w}} \cdot{ }^{22}$

Based on the classical model regarding the structure of alkane-surfactant aggregates formed in solution for alkane solubilization, the aggregates are assumed to be spherical with a layer of surfactant molecules on the surface. Thus, when solubilization reaches equilibrium, eqn (5) and (6) can be obtained based on mass balance of surfactant:

$$
\begin{gathered}
\frac{\Gamma A_{\mathrm{i}} C_{\text {hex }} M_{\text {hex }}}{\rho_{\text {hex }}} \times 10^{-3}+C_{\mathrm{w}}=C_{0} \\
A_{\mathrm{i}}=\frac{6}{d} \times 10^{-9}
\end{gathered}
$$

where $A_{\mathrm{i}}\left(\mathrm{m}^{2} \mathrm{~m}^{-3}\right)$ is the hexadecane-water specific interfacial area; $C_{0}\left(\mathrm{~mol} \mathrm{~L}^{-1}\right)$ is the total concentration of surfactant initially added; $C_{\text {hex }}\left(\mathrm{mol} \mathrm{\textrm {L } ^ { - 1 } )}\right.$ is the concentration of hexadecane solubilized in aqueous phase; $M_{\text {hex }}\left(\mathrm{g} \mathrm{mol}^{-1}\right)$ is molecular weight of the hexadecane; and $\rho_{\text {hex }}\left(\mathrm{g} \mathrm{cm}^{-3}\right)$ is the density of the hexadecane at given temperature $T(\mathrm{~K}) ; d(\mathrm{~nm})$ is the measured diameter of the aggregates. From eqn (3)-(6), the surfactant excess, $\Gamma$, of surfactant on the aggregate surface and the $C_{\mathrm{w}}$ for a given $C_{0}$ can be obtained. The area per surfactant molecule at the hexadecane-aqueous interface (namely the aggregate surface), $A\left(\mathrm{~m}^{2}\right)$, is obtained by eqn (7):

$$
A=\frac{1}{\Gamma N_{\mathrm{A}}}
$$

where $N_{\mathrm{A}}\left(6.022 \times 10^{23} \mathrm{~mol}^{-1}\right)$ is the Avogadro constant.

\section{Materials and methods}

\subsection{Materials}

SDBS (Sodium dodecylbenzenesulfonate, technical grade, purity > 97.0\%), Triton X-100 (polyoxyethylene (10) isooctylphenyl ether, laboratory grade, purity $>98.0 \%$ ), and hexadecane (purity $>99.0 \%$ ) were purchased from SigmaAldrich (St Louis, Mo., U.S.). Selected properties and molecular structures of SDBS and Triton X-100 are presented in Table 1 and Fig. 1, respectively. $n$-Octane (purity $>95.0 \%$ ) and HPLC grade ethanol were purchased from Damao Chemical (Tianjin, China). All other chemicals were of analytical grade and used as received. Ultra-pure water with an initial resistivity of 18.2 $\mathrm{M} \Omega \mathrm{cm}$ produced by UPT-II-40 (Ulupure, Chengdu, China) was used throughout the experiment. Phosphate buffer solution (PBS, $1.24 \mathrm{~g} \mathrm{~L}^{-1} \mathrm{KH}_{2} \mathrm{PO}_{4}$ and $1.35 \mathrm{~g} \mathrm{~L}^{-1} \mathrm{~K}_{2} \mathrm{HPO}_{4} \cdot 3 \mathrm{H}_{2} \mathrm{O}$, pH 6.8) was used as the background electrolyte solution to provide a stable concentration of counterions, which is important for application of the Gibbs adsorption equation for surfactant surface excess calculation.

\subsection{Interfacial tension measurement}

In order to obtain the CMCs of the surfactants and $\Gamma_{\max }$ and $K$ in eqn (3), interfacial tension between hexadecane and surfactant solution with designated surfactant concentrations was measured at $30{ }^{\circ} \mathrm{C}$ with a tensiometer (JZ-200A, Chengde, China) using the du Noüy ring method. ${ }^{23}$ In brief, $15 \mathrm{~mL}$ of surfactant PBS solution was prepared in a $50 \mathrm{~mL}$ glass beaker. $15 \mathrm{~mL}$ of hexadecane was then carefully added to the top of the surfactant solutions without disturbing the bulk volumes. Before the interfacial tension was measured, the beaker was 
Table 1 Selected properties and the water-hexadecane interface coefficients of the surfactants used in this study

\begin{tabular}{|c|c|c|c|c|c|c|c|}
\hline Surfactant & Formula & Surfactant type & $\begin{array}{l}\text { Molecular weight } \\
\left(\mathrm{g} \mathrm{mol}^{-1}\right)\end{array}$ & $\begin{array}{l}\mathrm{CMC}^{a} \\
(\mu \mathrm{M})\end{array}$ & $\begin{array}{l}\Gamma_{\max }^{b} \\
\left(\mathrm{~mol} \mathrm{~m}^{-2}\right)\end{array}$ & $\begin{array}{l}A_{\mathrm{m}}{ }^{c} \\
\left(\mathrm{~nm}^{2}\right)\end{array}$ & $\begin{array}{l}K^{d} \\
\left(\mathrm{~m}^{3} \mathrm{~mol}^{-1}\right)\end{array}$ \\
\hline SDBS & $\mathrm{C}_{12} \mathrm{H}_{25} \mathrm{C}_{6} \mathrm{H}_{4} \mathrm{SO}_{3} \mathrm{Na}$ & Anionic & 348.48 & 612 & $3.3 \times 10^{-6}$ & 0.50 & $0.2 \times 10^{3}$ \\
\hline
\end{tabular}

${ }^{a}$ Critical micelle concentration (CMC) measured in PBS solution at $30^{\circ} \mathrm{C} .{ }^{b}$ Maximum interface excess of surfactant. ${ }^{c}$ Area per surfactant molecule at $\Gamma_{\max }{ }^{d}$ Langmuir equation constant.

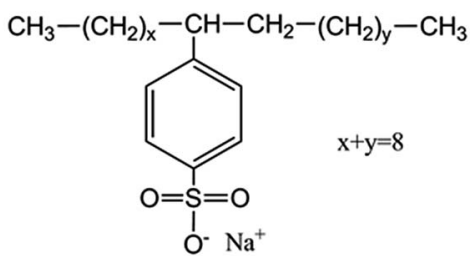

SDBS<smiles>COc1ccc(C(C)(C)CC(C)(C)C)cc1</smiles>

\section{Triton X-100}

Fig. 1 The molecular structure of SDBS and Triton X-100.

kept at $30^{\circ} \mathrm{C}$ for half an hour to allow partition of surfactant to water-hexadecane interface to reach equilibrium. The measurements were reproducible, with the difference of duplicate measurements within $\pm 0.2 \mathrm{mN} \mathrm{m}^{-1}$.

\subsection{Solubilization of hexadecane by surfactants}

Solutions of SDBS and Triton X-100 with hexadecane were prepared in triplicate using the following procedures. $50 \mu \mathrm{L}$ of hexadecane was pipetted to a $25 \mathrm{~mL}$ glass flask, and the flask was rotated to spread the hexadecane on the bottom of the flask. $10 \mathrm{~mL}$ of PBS solution of SDBS or Triton X-100 was then added to the flask and incubated on a reciprocal shaker at $30{ }^{\circ} \mathrm{C}$, $120 \mathrm{rpm}$ for $72 \mathrm{~h}$ to allow the solubilization to reach equilibrium (result of a preliminary test showed that hexadecane solubility does not change after $72 \mathrm{~h}$ ). Then the flasks were held stationary for $2 \mathrm{~h}$ to allow establishment of stable phase distributions. $4 \mathrm{~mL}$ of the aqueous solution was separated and collected using the method described by Zhong et al. ${ }^{14} 1 \mathrm{~mL}$ of the collected samples was removed for hexadecane concentration measurement, and another $2 \mathrm{~mL}$ was used for measurement on size and zeta potential of the aggregate particles. The hexadecane concentration was measured using gas chromatography (Agilent GC $6890 \mathrm{~N}$ ) following the procedures described by Zhong et al. ${ }^{14}$ Samples with $8000 \mu \mathrm{M}$ SDBS or with $1000 \mu \mathrm{M}$ Triton $\mathrm{X}-100$ were centrifugally filtered using 30KD ultrafiltration membrane (Millipore, Darmstadt, Germany) followed by hexadecane concentration measurement in the filtrate to check the partition of hexadecane. A control containing $10 \mathrm{~mL}$ surfactant solution and no hexadecane was used to quantify loss of surfactant due to adsorption to inner wall of the flasks. To examine the stability of solubilized hexadecane, $4 \mathrm{~mL}$ of the solubilized hexadecane solution obtained with $50 \mu \mathrm{M}$ SDBS or $25 \mu \mathrm{M}$ Triton X-100 were sealed and allowed to stand still for 48 hours. Then $3 \mathrm{~mL}$ of the solution were again separated using the method described by Zhong et $a .^{14}$ and hexadecane concentration was measured.

The size and zeta potential of aggregate particles were measured using a ZEN3600 Zetasizer Nano (Malvern Instruments, U.K.). The particle size was determined through dynamic light scattering (DLS) at $633 \mathrm{~nm}$ with $\mathrm{He}-\mathrm{Ne}$ laser, which worked on $4.0 \mathrm{mV}$ power. $1 \mathrm{~mL}$ of sample was loaded to the DTS-0012 cell and kept at $30{ }^{\circ} \mathrm{C}$. The scattered light was collected by receptor at angle of $173^{\circ}$ from light path. The size of the aggregates was expressed in terms of hydrodynamic diameter, which was calculated by using the software associated with the instrument. To obtain the zeta potential of the aggregates, approximately $1 \mathrm{~mL}$ of sample was loaded to the DTS1060 folded capillary cell and the electrophoretic mobility of the aggregate particles was measured at $30{ }^{\circ} \mathrm{C}$ under automatic voltage using laser Doppler velocimetry with M3-PALS technique to avoid electroosmosis. The measured data was converted into corresponding zeta potential applying the Helmholtz-Smoluchowski equation. ${ }^{24}$

\subsection{Cryo-transmission electron microscopy (cryo-TEM) observation of aggregates}

A $4 \mu \mathrm{L}$ drop of sample was placed on the copper grid, and then sent to a FEI Vitrobot sample plunger. The excess sample was removed with filter paper. The grid was then immediately plunged into a bath of liquid ethane and transferred to a bath of liquid nitrogen. The samples were stored in a GATAN model cryo-transfer unit in liquid nitrogen. The morphology of surfactant-hexadecane aggregates was viewed with a Tecnai F20 cryo-transmission electron microscope (FEI, Hillsboro, Oregon) at $120 \mathrm{kV}$.

\section{Results and discussion}

\section{1 $\quad \Gamma_{\max }$ and $K$}

The dependence of interfacial tension on the surfactant concentration is presented in Fig. 2a. The interfacial tension of hexadecane/PBS solution in the absence of surfactants is $41.3 \mathrm{mN} \mathrm{m}^{-1}$. For SDBS, hexadecane/PBS interfacial tension 

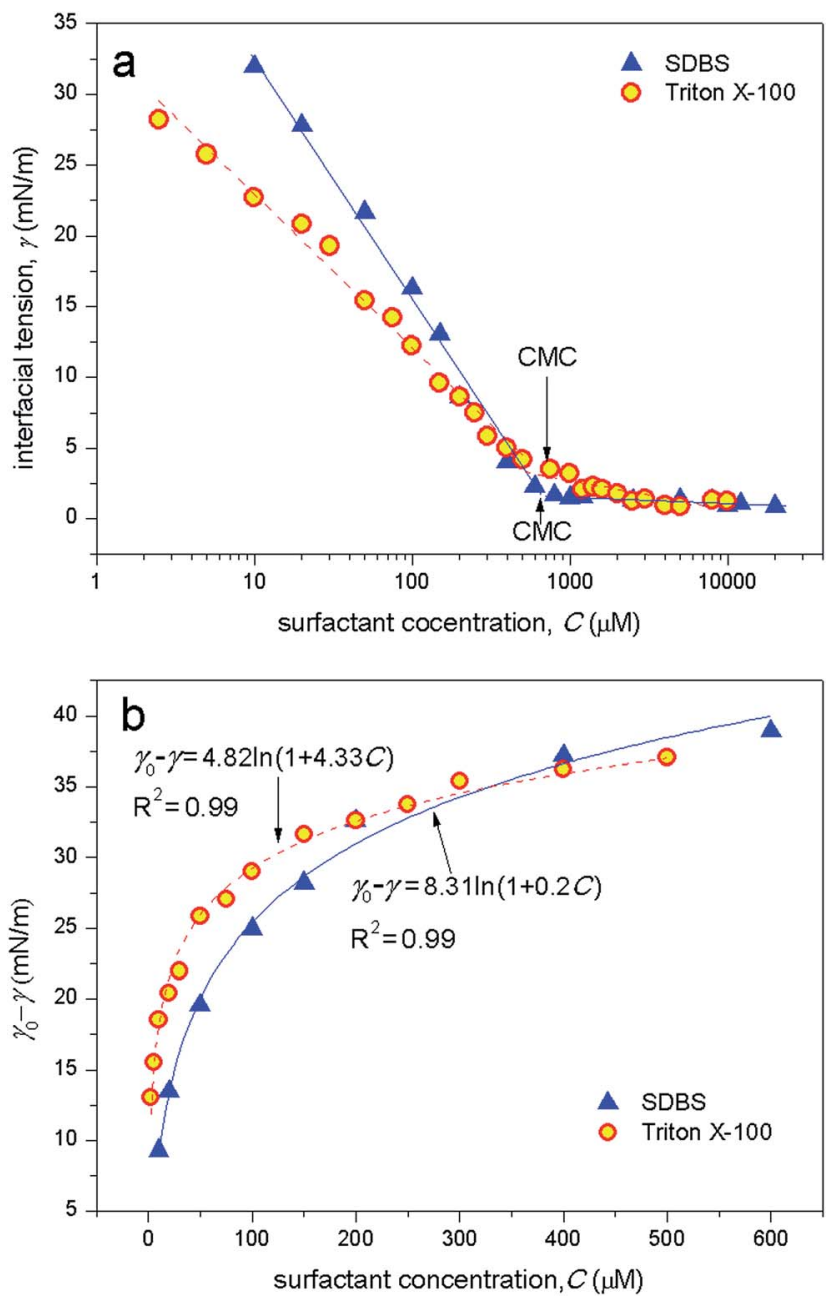

Fig. 2 (a) The hexadecane/PBS interfacial tension as a function of surfactant concentration. (b) Interfacial tension-concentration relation regression at surfactant concentrations below CMCs using Szyszkowski equation (eqn (3) in text).

decreases rapidly from 41.2 to $2.3 \mathrm{mN} \mathrm{m}^{-1}$ with increase of the SDBS concentration to approximately $600 \mu \mathrm{M}$. Further increase in SDBS concentration has minimal effect on the interfacial tension. For Triton X-100, the interfacial tension decreases from 41.3 to $4.2 \mathrm{mN} \mathrm{m}^{-1}$ with increase in the Triton X-100 concentration to approximately $500 \mu \mathrm{M}$. Further increase in Triton $\mathrm{X}-100$ concentration slowly reduces the interfacial tension from 4.2 to $1.4 \mathrm{mN} \mathrm{m}^{-1}$.

CMCs of the surfactants were obtained using the method described by Zhong et al. ${ }^{25}$ The CMC of SDBS is $612 \mu \mathrm{M}$, which is lower than in pure water (e.g. $2764 \mu \mathrm{M}$ reported by Yang et al. ${ }^{26}$ ) due to the presence of counterions (i.e., $\mathrm{K}^{+}$) in PBS in this study. The CMC of Triton X-100 is $672 \mu \mathrm{M}$, which is in the range of 200-900 $\mu \mathrm{M}$ reported by Sigma-Aldrich. ${ }^{27}$ The significantly different CMCs for PBS versus water obtained for SDBS compared to the similar values obtained for Triton is consistent with the anionic and nonionic natures of the two, respectively.

The interfacial tension data at surfactant concentrations below CMC were well fitted by the logarithmic function described by eqn (3) (Fig. 2b), and the maximum interface excess of surfactant $\left(\Gamma_{\max }\right)$ and the Langmuir constant $(K)$ were thus obtained. Minimal surfactant molecule area at interface $\left(A_{\mathrm{m}}\right)$ was calculated using eqn (7). The results are summarized in Table 1.

\subsection{Solubilization of hexadecane by surfactants}

As shown in Table $\mathrm{S} 1, \uparrow$ concentration of hexadecane solubilized by $50 \mu \mathrm{M}$ SDBS or $25 \mu \mathrm{M}$ Triton X-100 after standing for 48 hours is essentially identical to the initial concentration. $50 \mu \mathrm{M}$ and $25 \mu \mathrm{M}$ are lower end concentrations, respectively, for SDBS and Triton X-100 used in this study. The results demonstrate good stability of the solubilized hexadecane. Results of hexadecane solubilization by SDBS and Triton X-100 are presented in Fig. 3. Both surfactants increase the solubility of hexadecane at surfactant concentrations lower than CMC. The apparent solubility of hexadecane increased linearly with surfactant concentration for both surfactants, with different slopes below and above CMC. Solubilization capacity of a surfactant for an HOC is characterized by the molar solubilization ratio (MSR), which is defined as increase of solubilized
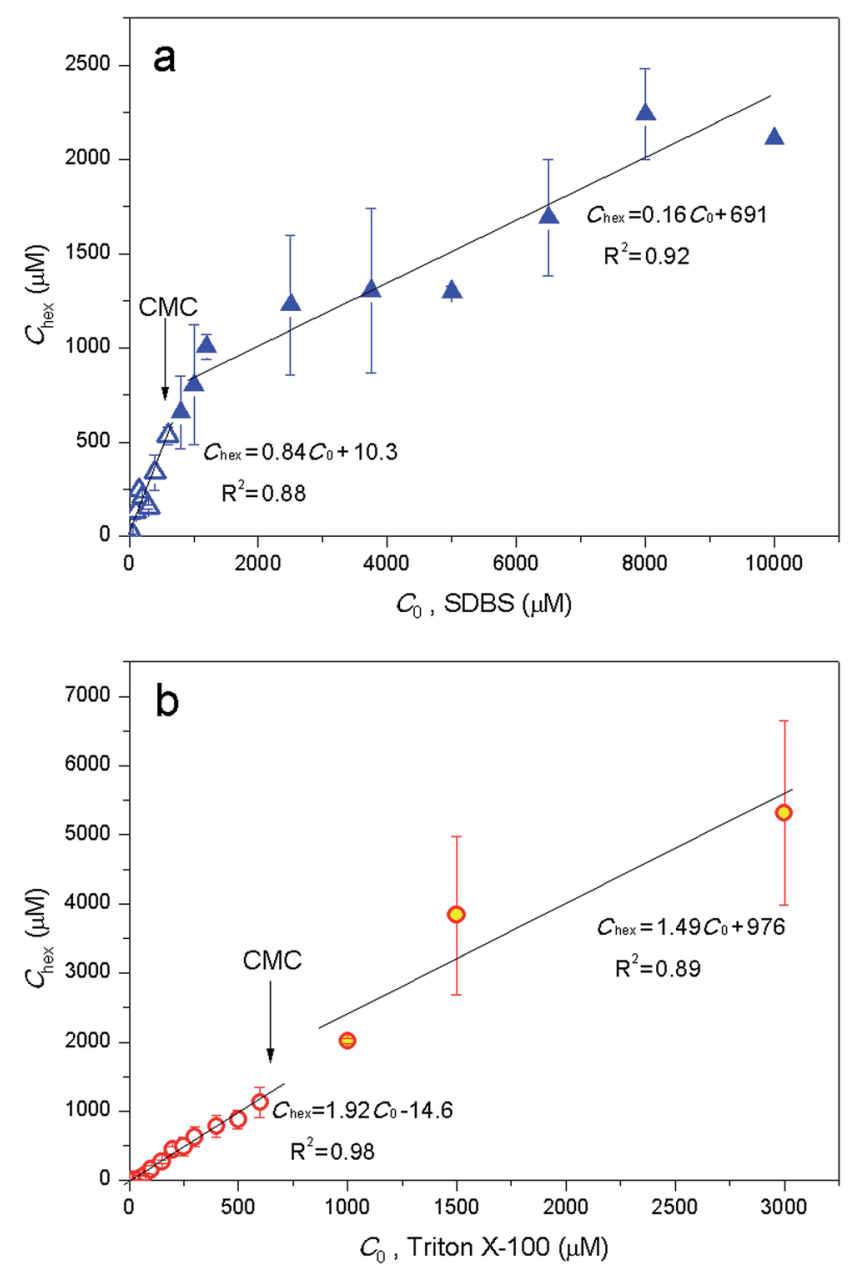

Fig. 3 Apparent hexadecane solubility $\left(C_{\text {hex }}\right)$ versus total surfactant concentration $\left(C_{0}\right)$ of (a) SDBS and (b) Triton X-100. Two sets of regression represent data for below and above the CMCs. 
hydrophobic compound concentration $\left(\mathrm{mol} \mathrm{L}^{-1}\right)$ per unit increase of surfactant concentration $\left(\mathrm{mol} \mathrm{L}^{-1}\right)$ in the solution. ${ }^{12,28}$ As shown from Fig. 3a, the MSR for SDBS is significantly higher below CMC than above CMC (i.e. 0.84 and 0.16, respectively). Similar results were observed for an ionic rhamnolipid biosurfactant in the solubilization of hexadecane $\mathbf{~}^{\mathbf{1 4}}$ and octadecane. ${ }^{6}$ In contrast, MSRs for Triton X-100 are not significantly different below and above CMC (1.9 and 1.5, Fig. 3b), indicating the influence of surfactant molecule structure on solubilization behavior.

\subsection{Size and zeta potential of aggregates}

Formation of aggregates at surfactant concentrations both below and above CMC is demonstrated by the results of aggregate size measurement using DLS method (Fig. 4) and by direct view of the aggregates with cryo-TEM (Fig. S1, ESI $\dagger$ ). Also, the spherical aggregate assumption was confirmed by the sphere morphology of the aggregates. Although multiple groups of particles with different size range (two or three peaks in the intensity and volume of particles distributions (\%) plots, Fig. S2†) were detected by DLS particle size measurement, almost $100 \%$ of the particles in numbers are in the group of the smallest size (Fig. S2 and S3†). This is consistent with the results of the cryo-TEM measurements, in which only one group of particles with similar size was observed (Fig. S1†). For both surfactants, the particle size decreases rapidly with increase of $C_{0}$ to approximately $200 \mu \mathrm{M}$, and then stabilizes as $C_{0}$ continues to increase to above CMC (Fig. 4).

As shown in Fig. 5, for anionic surfactant SDBS, the zeta potential of aggregates decreases approximately from $-20 \mathrm{mV}$ to $-35 \mathrm{mV}$ with increase of $C_{0}$ from $25 \mu \mathrm{M}$ to $200 \mu \mathrm{M}$, and stabilizes at $\sim-35 \mathrm{mV}$ with further increasing $C_{0}$ to $800 \mu \mathrm{M}$. Similar trend was observed by Ivanov et al. ${ }^{29}$ for zeta potential of hexadecane emulsion drops versus concentration of ionic surfactant SDS at significantly low SDS concentrations. When $C_{0}$ is even further increased to $1200 \mu \mathrm{M}$, a secondary decrease of zeta potential to $\sim-70 \mathrm{mV}$ is observed. In contrast, the zeta

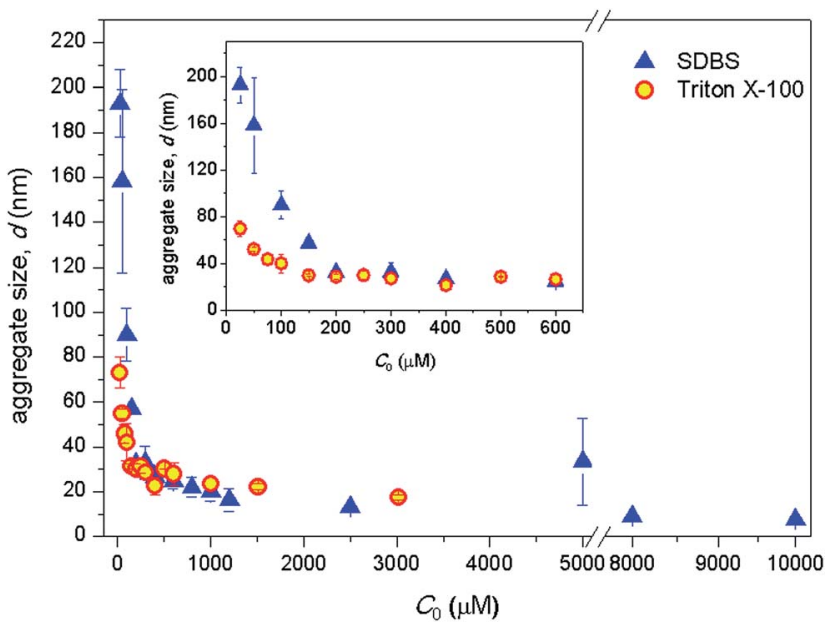

Fig. 4 Aggregate size $(d)$ versus the total surfactant concentration $\left(C_{0}\right)$ for hexadecane solubilization. (Inset) zoom-in for $C_{0}$ lower than CMC.

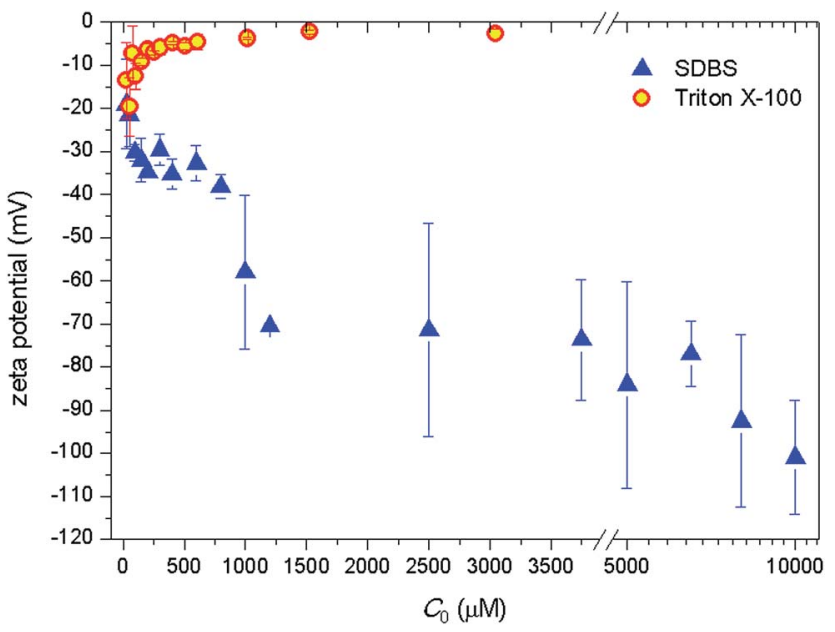

Fig. 5 Zeta potential of aggregates versus the total surfactant concentration $\left(C_{0}\right)$ for the hexadecane solubilization.

potential of hexadecane-Triton X-100 aggregates increased from $-20 \mathrm{mV}$ to $-5 \mathrm{mV}$ with increasing $C_{0}$ from $50 \mu \mathrm{M}$ to $1000 \mu \mathrm{M}$ and stabilized at $\sim-5 \mathrm{mV}$ when $C_{0}$ was above $1000 \mu \mathrm{M}$. Zeta potential is the potential difference between the bulk solution of the dispersion medium and the slippery layer of fluid attached to the dispersed particle. ${ }^{\mathbf{2 4}, 30}$ Due to the anionic hydrophilic heads of SDBS, the aggregates have negatively charged surface. ${ }^{31}$ The negatively charged surface of aggregates for non-ionic Triton X-100 probably results from association of anions in $\mathrm{PBS}$ (i.e. $\mathrm{OH}^{-}, \mathrm{HPO}_{4}{ }^{2-}, \mathrm{H}_{2} \mathrm{PO}_{4}{ }^{-}, \mathrm{PO}_{4}{ }^{3-}$ ) with the polyoxyethylene chain of Triton on the aggregate surface.

\subsection{Partitioning of surfactants and its relation with aggregation}

No emulsion of hexadecane in the presence of surfactants was observed in the experiments. Adsorption of the surfactants to the inner wall of the flask was also minimal (data not shown). Because very limited volume of hexadecane $(50 \mu \mathrm{L})$ was used, partition of surfactants to the hexadecane phase, or to the interface between the floating mass of hexadecane and the aqueous phase (less than $1 \mathrm{~cm}^{2}$ in contrast to the magnitude of $10^{2}$ to $10^{4} \mathrm{~cm}^{2}$ for the total surface area of the aggregates according to calculation below), was minimal. Therefore, the surfactants reside either in bulk aqueous solution or in the aggregate. The hexadecane concentration in the filtrate after ultrafiltration was under the detection limit (data not shown), showing that the amount of freely-dissolved hexadecane in bulk aqueous phase is minimal and all the solubilized hexadecane is associated with the aggregate. This is consistent with the fact that hexadecane has extremely low water solubility $\left(0.09 \mu \mathrm{g} \mathrm{L}^{-1}\right.$, $25{ }^{\circ} \mathrm{C}$ ) and high octanol-water partition coefficient $\left(10^{8.3}, 25\right.$ $\left.{ }^{\circ} \mathrm{C}\right) .{ }^{32}$ Hence, based on the spherical aggregate assumption, the aggregate surface excess $\Gamma$ and the bulk concentration $C_{\mathrm{w}}$ of surfactants were calculated by applying eqn (2) and (5) using $\Gamma_{\max }$ and $K$ previously obtained.

For both SDBS and Triton X-100, a linear relationship between the apparent solubility of hexadecane, $C_{\mathrm{hex}}$, and the 
freely-dissolved surfactant monomer concentration, $C_{\mathrm{w}}$, is observed with increase of $C_{\mathrm{w}}$ to CMC (Fig. 6a). This is similar to the relationship between $C_{\text {hex }}$ and the total surfactant concentration, $C_{0}$ (Fig. 3). By comparing the slopes of $C_{\text {hex }}-C_{0}$ profile at $C_{0}$ below CMC and $C_{\mathrm{hex}}-C_{\mathrm{w}}$ profile (0.84 versus 1.0 for SDBS, and 1.9 versus 2.5 for Triton $\mathrm{X}-100$ ), the relative distribution of the surfactant between the freely-dissolved and aggregateassociated is calculated. The percentage of the aggregateassociated surfactant is approximately $16 \%$ and $23 \%$ of the total for SDBS and Triton X-100, respectively.

Changes of surfactant surface excess $(T)$ and molecule area (A) versus $C_{\mathrm{w}}$ are presented in Fig. 6b. For SDBS, a rapid increase of $\Gamma$ and decrease of $A$ are observed when $C_{\mathrm{w}}$ increases from $\sim 25 \mu \mathrm{M}$ to $\sim 150 \mu \mathrm{M}$. Further increase of $C_{\mathrm{w}}$ causes asymptotic approach of $\Gamma$ and $A$ to $\Gamma_{\max }$ and $A_{\mathrm{m}}$, respectively. Conversely, there is only a minor increase in $\Gamma$ for Triton X-100. Only very slight increase of $\Gamma$ and decrease of $A$ are observed when $C_{\mathrm{w}}$ was below $\sim 80 \mu \mathrm{M} . \Gamma$ and $A$ are more sensitive to change of $C_{\mathrm{w}}$ with a smaller $K$ according to eqn (2) and (7). The $K$ value for Triton $\mathrm{X}-100$ is much larger than for SDBS $\left(4.33 \times 10^{3}\right.$ and $0.2 \times 10^{3} \mathrm{~m}^{3}$
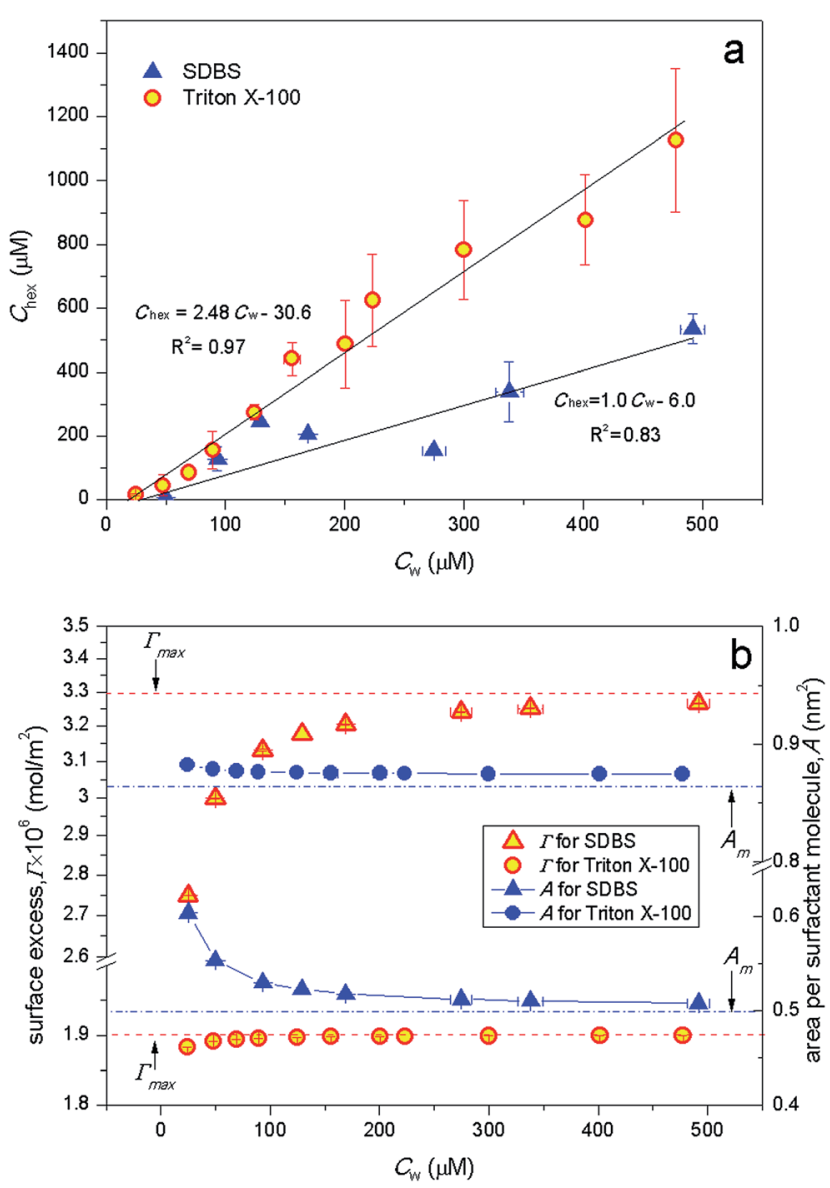

Fig. 6 (a) Apparent solubility of hexadecane $\left(C_{\text {hex }}\right)$ versus the bulk surfactant concentration $\left(C_{\mathrm{w}}\right)$ at $C_{\mathrm{w}}$ below CMCs; (b) surface excess $(I)$ and molecule area $(A)$ of surfactants on the aggregates surface versus surfactant bulk concentration $\left(C_{w}\right)$. The dash lines and dash dot lines represent the maximum surface excess $\left(\Gamma_{\max }\right)$ and the minimum area per surfactant molecular on the surface $\left(A_{m}\right)$, respectively. $\mathrm{mol}^{-1}$, respectively (Table 1)). Thus, a more significant change of $\Gamma$ and $A$ over a broader range of $C_{\mathrm{w}}$ occurred for SDBS.

As shown in Fig. 7, for both surfactants, aggregate size, $d$, decreases with the increase of surfactant surface excess on the aggregates, $\Gamma$, in a way that $d$ approaches the stabilized minimum aggregate size $\left(d_{\min }\right)$ as $\Gamma$ approaches $\Gamma_{\max }$. This result indicates that the curvature of the aggregate surface increases with increasing surface density of surfactant molecules. For SDBS, which has charged hydrophilic head, as SDBS molecules approach each other ( $T$ increases and $A$ decreases) on the aggregate surface, the electrostatic repulsion between charged heads of SDBS becomes stronger. Such enhancement in electrostatic repulsion induces unequal rate of approach for polar and hydrophobic moieties between molecules, and therefore increase in aggregate surface curvature (Fig. 8). Thus, the aggregate size, $d$, decreases with increasing $\Gamma$. Similarly, as the polar head of Triton X-100 molecule, the polyoxyethylene chain, usually twists and curls, causing large actual molecule radius, ${ }^{33}$ the spatial steric repulsion between Triton X-100 polar heads may act in a way similar to electrostatic repulsion between charged heads in SDBS molecules, thus also causing an increase in surface curvature of aggregates (Fig. 8).

Zeta potential is a function of particle size and surface charge density. ${ }^{\mathbf{2 4 , 3 4 , 3 5}}$ Because SDBS is an anionic surfactant with a polar head that fully dissociates in solution, surface charge density is determined by surface molecule density, or $\Gamma$. Also, as discussed above, particle size is also a function of $\Gamma$. For SDBS, therefore, zeta potential is essentially a dependent of $\Gamma$ and its change also exhibits an asymptotic pattern at concentrations lower than CMC. For Triton X-100, binding of anions, i.e. $\mathrm{H}_{2} \mathrm{PO}_{4}{ }^{-}, \mathrm{HPO}_{4}{ }^{2-}$ and $\mathrm{OH}^{-}$, to the polyoxyethylene group through hydrogen bond may be responsible for the negative zeta potential of the aggregates. As $\Gamma$ increases, the Triton X-100 molecules become more compacted on the aggregate surface, leaving less space for the anions to partition. Consequently zeta potential increases.

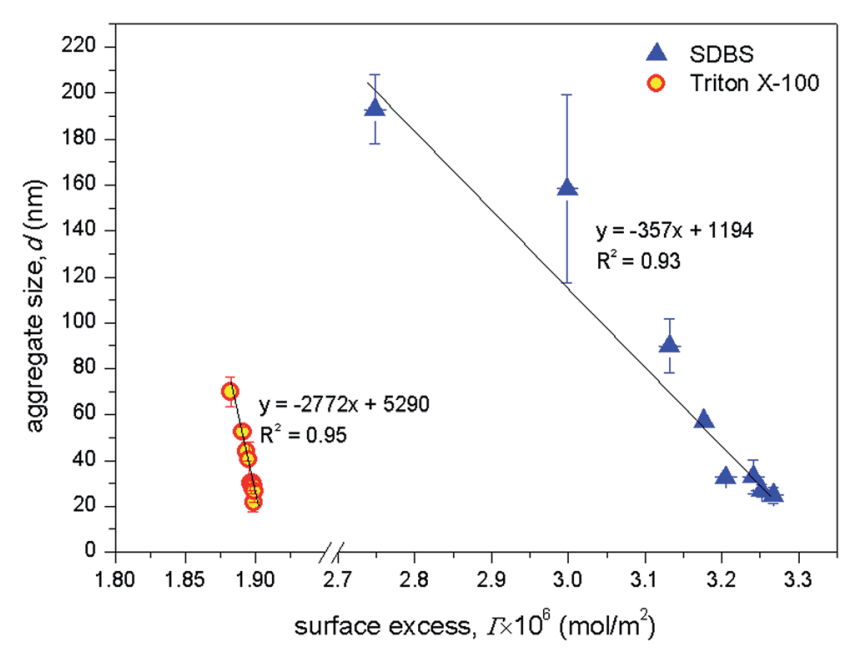

Fig. 7 Aggregates diameter $(d)$ and surface excess of surfactants $(\Gamma)$ versus the bulk surfactant concentration $\left(C_{w}\right)$ blow CMCs. 


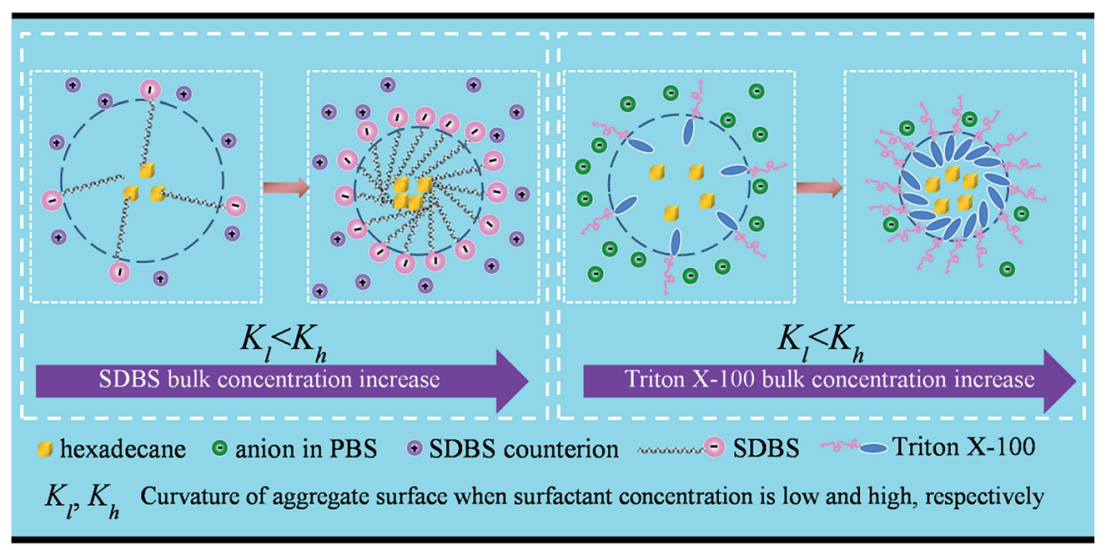

Fig. 8 Schematic diagram of aggregate formation at surfactant concentration below CMCs and the change of curvature of aggregates surface with increasing surfactant bulk concentration for the hexadecane solubilization by surfactant.

For the standard surfactant solubilization conceptualization, enhancement of HOC solubility requires surfactant concentrations higher than CMC..$^{28,36-38}$ In contrast, results in this study show that significant hexadecane solubility enhancement takes place at surfactant concentrations lower than CMC and such enhancement is related to formation of aggregates. We speculate that the presence of hexadecane has some influence on surfactant monomer activity through the hydrophobic interaction between surfactant and hexadecane molecules, which may be more significant than between surfactant molecules themselves. Thus, the interaction between surfactant and hexadecane molecules may favor formation of aggregates below CMC.

\section{Conclusion}

In contrast to the conceptualized micelle-based mechanism for solubilization of HOCs starting at surfactant concentration higher than CMC, the results of this study demonstrated that SDBS and Triton X-100 at sub-CMC concentrations can enhance hexadecane solubilization employing an aggregate formation mechanism. Observation of sub-CMC aggregates by both DLS and cryo-TEM methods suggests that HOC-surfactant interaction contributes to sub-CMC aggregate formation. This study presents an initial analysis of the sub-CMC solubilization of HOCs by surfactants. The study is of importance for better understanding the solubilization behavior of HOCs by surfactants and for economical application of surfactants. Future studies should aim at testing such sub-CMC solubilization behavior for a variety of surfactants and HOCs.

\section{Acknowledgements}

The authors thank the Center for Integrative Imaging (CII) at University of Science and Technology of China for cryo-TEM analysis. This study was funded by the National Student Innovation Training Program (SIT) of China (521611246), the National Natural Science Foundation of China (51378192, 51378190, 51308200 and 51108166), the Program for
Changjiang Scholars and Innovative Research Team in University (IRT-13R17). Additional support was provided by the NIEHS Superfund Research Program (P42 ES04940).

\section{References}

1 L. M. Abriola, C. D. Drummond, E. J. Hahn, K. F. Hayes, T. C. G. Kibbey, L. D. Lemke, K. D. Pennell, E. A. Petrovskis, C. A. Ramsburg and K. M. Rathfelder, Environ. Sci. Technol., 2005, 39, 1778-1790.

2 J. Childs, E. Acosta, M. D. Annable, M. C. Brooks, C. G. Enfield, J. H. Harwell, M. Hasegawa, R. C. Knox, P. S. Rao, D. A. Sabatini, B. Shiau, E. Szekeres and A. L. Wood, J. Contam. Hydrol., 2006, 82, 1-22.

3 R. Masrat, M. Maswal and A. A. Dar, J. Hazard. Mater., 2013, 244, 662-670.

4 K. D. Pennell, L. M. Abriola and W. J. Weber Jr, Environ. Sci. Technol., 1993, 27, 2332-2340.

5 D. E. Kile and C. T. Chiou, Environ. Sci. Technol., 1989, 23, 832-838.

6 Y. Zhang and R. M. Miller, Appl. Environ. Microb., 1992, 58, 3276-3282.

7 J. E. McCray, G. Bai, R. M. Maier and M. L. Brusseau, $J$. Contam. Hydrol., 2001, 48, 45-68.

8 T. B. Boving and M. L. Brusseau, J. Contam. Hydrol., 2000, 42, 51-67.

9 J. S. Clifford, M. A. Ioannidis and R. L. Legge, J. Colloid Interface Sci., 2007, 305, 361-365.

10 J. D. Albino and I. M. Nambi, J. Environ. Sci. Health, Part A: Environ. Sci. Eng., 2009, 44, 1565-1573.

11 A. Patist, J. R. Kanicky, P. K. Shukla and D. O. Shah, J. Colloid Interface Sci., 2002, 245, 1-15.

12 M. A. Mir, O. A. Chat, M. H. Najar, M. Younis, A. A. Dar and G. M. Rather, J. Colloid Interface Sci., 2011, 364, 163-169.

13 A. R. Tehrani-Bagha and K. Holmberg, Materials, 2013, 6, 580-608.

14 H. Zhong, Y. Liu, Z. F. Liu, Y. B. Jiang, F. Tan, G. M. Zeng, X. Z. Yuan, M. Yan, Q. Y. Niu and Y. S. Liang, Int. Biodeterior. Biodegrad., 2014, 94, 152-159. 
15 U. Zoller, Environ. Int., 2006, 32, 269-272.

16 S. S. Talmage, Environmental and human safety of major surfactants: alcohol ethoxylates and alkylphenol ethoxylates, CRC Press, 1994.

17 S. Rebello, A. K. Asok, S. Mundayoor and M. Jisha, Environ. Chem. Lett., 2014, 12, 275-287.

18 K. Hill and C. LeHen-Ferrenbach, in Sugar-based surfactants fundamentals and Applications, ed. C. C. Ruiz, CRC Press, Boca Raton, 2008.

19 R. Höfer and K. Hinrichs, in Polymers-Opportunities and Risks II: Sustainability, Product Design and Processing, Springer, Berlin, Heidelberg, 2010, pp. 97-145.

20 K. Hill and R. Höfer, in Sustainable Solutions for Modern Economies, ed. R. Höfer, RSC Publishing, Cambridge, 2009, pp. 167-237.

21 L. Chen and T. C. Kibbey, Langmuir, 2006, 22, 6874-6880.

22 M. J. Rosen, Surfactants and Interfacial Phenomena, John Wiley \& Sons, Hoboken, 3rd edn, 2004.

23 X. Z. Yuan, F. Y. Ren, G. M. Zeng, H. Zhong, H. Y. Fu, J. Liu and X. M. Xu, Appl. Microbiol. Biotechol., 2007, 76, 11891198.

24 R. J. Zasoski, in Encyclopedia of Soil Science, ed. W. Chesworth, Springer, Netherlands, Dordrecht, 2008, pp. 841-845.

25 H. Zhong, G. M. Zeng, J. X. Liu, X. M. Xu, X. Z. Yuan, H. Y. Fu, G. H. Huang, Z. F. Liu and Y. Ding, Appl. Microbiol. Biotechnol., 2008, 79, 671-677.

26 K. Yang, L. Zhu and B. Xing, Environ. Sci. Technol., 2006, 40, 4274-4280.
27 Sigma-Aldrich, Selected properties of Triton X-100, http:// www.sigmaaldrich.com/catalog/product/sial/x100?

lang $=$ zh\&region $=\mathrm{CN}$ [In Chinese], (accessed April 8, 2015).

28 D. A. Edwards, R. G. Luthy and Z. Liu, Environ. Sci. Technol., 1991, 25, 127-133.

29 I. B. Ivanov, K. G. Marinova, K. D. Danov, D. Dimitrova, K. P. Ananthapadmanabhan and A. Lips, Adv. Colloid Interface Sci., 2007, 134, 105-124.

30 D. Q. Lin, L. N. Zhong and S. J. Yao, Biotechnol. Bioeng., 2006, 95, 185-191.

31 W. Liu, J. Kumar, S. Tripathy and L. A. Samuelson, Langmuir, 2002, 18, 9696-9704.

32 NCBI, PubChem Compound Database; CID $=11006$, selected properties of $n$-hexadecane, http:// pubchem.ncbi.nlm.nih.gov/compound/11006, (accessed May 8, 2015).

33 J. Penfold, I. Tucker, R. Thomas, E. Staples and R. Schuermann, J. Phys. Chem. B, 2005, 109, 10760-10770.

34 D. A. Dzombak and F. M. M. Morel, Surface Complex Modeling: Hydrous Ferric Oxide, John Wiley \& Sons, New York, 1990.

35 R. J. Hunter, Zeta Potential in Colloid Science. Principles and Applications, Academic Press, New York, 1981.

36 G. Bai, M. L. Brusseau and R. M. Miller, J. Contam. Hydrol., 1998, 30, 265-279.

37 C. L. Chun, J.-J. Lee and J.-W. Park, Environ. Pollut., 2002, 118, 307-313.

38 S. Paria, Adv. Colloid Interface Sci., 2008, 138, 24-58. 